\title{
Dr. Alfredo Martén Obando (QdDG)
}

Pocas semanas antes de su muerte, el Dr. Martén se me acercó un día en el Hospital México para contarme que tenía un trabajo de revisión sobre el abordaje del paciente ictérico que deseaba enviar para publicación en AMC, pero deseaba saber si la revista tenía algún requisito especial para estos trabajos. Como suelo hacer con todos los que me abordan con este tipo de inquietud, le expresé que estaríamos encantados de revisarlo. A los días me dijo que ya lo tenía casi listo, que sólo le quedaba por arreglar algunas de las referencias pero que seguro nos lo haría llegar la siguiente semana.

Desafortunadamente él no pudo hacerlo en persona ya que el si-guiente fin de semana falleció. Sin embargo, el trabajo fue entregado a nosotros por su viuda, la Sra. Mirtha Miranda, y lo publicamos entre las revisiones del presente número de AMC.

Los miembros del comité editorial de AMC hemos deseado aprovechar la oportunidad para hacer un pequeño homenaje a este maestro de tantas generaciones de médicos, especialmente de aquellos formados en las aulas del CENDEISSS y del Hospital México. Para ello transcribimos a continuación la reseña que su hijo, Ricardo Martén, hiciera de él el día de su funeral y las palabras que su amigo, el Dr. Ignacio Salom, le dedicara en un acto de homenaje en la Universidad de Costa Rica.

\section{Reseña por Ricardo Martén}

Alfredo Martén Obando fue siempre una persona excepcional. Quienes lo conocimos, lo admiramos por su integridad, su humildad, su ímpetu intelectual y su excelente sentido del humor. Es difícil recordar la vida de alguien a quien quisimos tanto cuando acaba de partir. Pero, a pesar del terrible dolor, a pesar del vacío que apenas empezamos a asimilar, cuando recordemos a mi papá es justo y consecuente hacerlo con una sonrisa.

La genialidad de Alfredo Martén era tal que en ocasiones podía ser una persona acaso incomprensible o inescrutable. Muchas veces trate de entender su lógica para ver las cosas, sus mecanismos emocionales y los motivos para sus acciones. Es cierto que era una persona muy reservada, recelosa de sus intimidades, amante de una soledad muy particular, que apenas entendí a la distancia. Pero también fue un hombre con una capacidad enorme para cultivar la amistad, y con un afán inconmensurable por disfrutar la vida de la forma que él consideraba apropiada.

Si algo le agradezco a mi papá fue que nos enseñó a buscar la diferencia, a buscar ese detalle que nos hiciera ver otras facetas de la vida. Los convencionalismos y la rutina no encajaban, en lo absoluto, con su intensidad; prefería tomar el riesgo de lo desconocido antes de someterse a la ligereza de lo esperado. Por eso jamás se sintió obligado a tener un carro lujoso, ni a tener una casa grande y elegante, ni a disponer de otros para hacer las cosas que él podía, y disfrutaba hacer. Todo lo contrario: mi papá siempre prefirió lavar y aplancharse él mismo sus inmaculadas camisas blancas, prefirió comprarse discos de música clásica y pinturas antes de tener una computadora, prefirió un hogar sencillo y simple, con apenas unos muebles, antes de desvivirse por una escenografía de vida materialista desligada de sus intereses personales. Sus pasiones no estaban en los objetos, vivían en los sentidos: el sonido que le transmitía Toscanini, el gusto de un buen vino tinto francés, la textura de una corbata, el aroma de Londres durante

ISSN 0001-6002/2005/47/1/3-6 Acta Médica Costarricense, (C2005 Colegio de Médicos y Cirujanos

la primavera o la imagen de esa Costa Rica utópica y rural en las pinturas de Fausto Pacheco. 
Su dialéctica intelectual era sencilla: la medicina y la música. Como médico, su labor es imposible de resumir o siquiera sintetizar. Le provocaba tal placer su especialidad que la hizo parte de nuestras vidas. Mis hermanas y yo crecimos aprendiendo fechas históricas en la escuela y técnicas de gastros-copías en la casa. Pasábamos horas con él deambulando por los laberintos internos del Hospital México, subiendo y bajando pisos, conversando con el personal, sintiéndonos cómplices de una dinámica que sin él era imposible conocer. Tal era su vocación que siempre se mantuvo investigando, leyendo y ampliando sus conocimientos alrededor de esa herramienta que le permitió conocer el país. Mientras atendió la consulta externa, mi papá conoció Costa Rica a través de sus cientos de pacientes, escuchando sus historias, sus problemas, sus sueños, sus limitaciones. Y ahí debió comprender lo absurdo de planear en exceso la vida, y lo importante de disfrutar la felicidad cuando existe, y la necesidad de entender la tristeza si ésta se presenta. Para él, no queda duda, ser médico nunca tuvo que ver con una imagen prefabricada, ser médico era una responsabilidad con el país, con un modelo social pluralista y con cada uno de los pacientes que lo visitó. Ante todo, le dedicó su profesión al Seguro Social, porque sabía que antes del lucro personal, la práctica de la medicina en un hospital del estado le permitía darle esperanza a muchas más personas que verdaderamente lo necesitaban.

Su otra gran pasión era la docencia. Detrás de ese carácter fuerte, y de su altísima exigencia, mi papá forjó una admirable relación con cientos de estudiantes de medicina. $\mathrm{Y}$ a muchos les hizo ver que para ser un buen médico, no bastaba con ser un excelente estudiante de la materia: había que tener sed de conocimiento, de arte, de literatura, y por encima de todo, de lealtad y amistad. Me reconforta saber que de alguna forma, para muchos de ellos también fue un padre ejemplar. La Universidad de Costa Rica era su casa, la fuente de muchos de sus principios y la base de muchas de sus creencias. Gracias a la U.C.R., Alfredo Martén fue un dirigente estudiantil, un excelente profesional y un visionario. Asistir a las asambleas de escuela era para él una necesidad, para seguir sintiéndose parte de la institución. Y más allá de esos detalles, lo que más agradeció fue que tanto el hospital como la universidad le dieron grandes amigos y compañeros.

Muchas veces mi papá comentó que le habría gustado ser músico. Se notaba una ansiedad cada vez que lo decía, tal vez recriminándose el sentir esa nostalgia por afinar un violín o por sostener el arco. Y aunque no fue su vocación final, la música clásica determinó en gran parte su vida, sus decisiones y su carácter. A pesar de su formación científica, supo que el arte era necesario y fundamental. Sabía que la música le daba todo eso que ya era inalcanzable a simple vista. Cerraba los ojos sentado en el sillón y allí, solo, en su interior, quisiera creer que alcanzaba un estado mayor, buscando esas notas sublimes, buscando siempre secuencias, órdenes, patrones y recorridos cadenciosos, inexplicables con palabras pero tan elocuentes para el corazón y el alma.

El legado profesional de mi papá es motivo de orgullo para mí y para quienes lo conocieron. Pero quienes fuimos su familia, tuvimos la dicha de conocer facetas de él que quizás muchos desconocen. A pesar de lo que pudiera aparentar, y de su muy particular historial matrimonial, mi papá fue, por encima de todo, un hombre de familia. Le gustaba almorzar con la gente que quería, patrocinando dinámicas exquisitas, depurando toda una mitología familiar que incluía películas de vampiros protagonizadas por Christopher Lee, ejercicios de confianza que terminaban en ataques de cosquillas, desafortunados días de campo con aguaceros torrenciales, numerosos tanques vacíos de gasolina con distancias largas aún por recorrer, larguísimas caminatas con mi hermana embarazada. Me provoca alegría recordar que fue médico honorario del equipo de natación de Plaza Víquez, que nos examinaba nuestra capacidad de reconocer instrumentos musicales, su enorme amor por los perros, su anhelo por una vida en Inglaterra con la obligada pinta de cerveza, sus terribles hábitos alimenticios y los antojos que tenía a todas horas, sus discusiones airadas con taxistas, la manera en que nos pellizcaba los pulgares, el sonido de sus llaves colgándole del cinturón y el olor de su cara cuando terminaba de rasurarse.

Aceptar que todo eso es parte del pasado es duro y triste. Pero también me obliga, y nos obliga, a fortalecer nuestra memoria, a intensificar cualquier recuerdo que tengamos de él y no dejar que con el tiempo se diluya. Alfredo Martén Obando merece un sitio privilegiado; cuando pensemos en él, y recordemos su pequeña figura, con su camisa blanca, su corbata impecable y sus zapatos lustrados, también recordemos su enorme corazón, agradezcamos la oportunidad que tuvimos de conocerlo y analizarlo. Y así como en la estructura sinfónica, en la cual un tema se mantiene recurrente a lo largo de la obra, pensemos que la vida de mi papá todavía sigue en un infinito cuarto movimiento, que parece no terminar nunca, donde todos los instrumentos de la orquesta parecen celebrar la idea que nadie los callará y que, por una vez, la idea del final no existe.

\section{Semblanza por Dr. Ignacio Salom}

Distintas variables se conjugan para hacer de una semblanza de Alfredo Martén un reto interesante. Definitivamente no fue un personaje que pasó desapercibido por el mundo, donde él estuviera dejaba huella. Despertaba reacción y de la intensa, tanto para bien como para mal. Conjugaba una extraordinaria inteligencia con un temperamento ocasionalmente feroz, para ubicarlo en la clasificación moderna sobre inteligencia emocional de Daniel Goleman.

No me perdonaría mi amigo de muchos años que lo retrate en este momento tan importante para su memoria 
como un personaje desteñido y sumiso adherente de las corrientes trasnochadas de la sociocultura. Sería tan absurdo como pretender de mi parte adjudicarle indultos para sacarlo del purgatorio donde lo ubicó el cura en el sermón de su sepelio y elevarlo a contrapelo al cielo. Ante esta disyuntiva, es probable que Alfredo hubiese preferido estar entre nosotros, es decir, un poco en el infierno.

Le interesaba hacer amigos, quedar bien, pero no con todo el mundo.

Utilizaba el látigo verbal como uno de sus medios de comunicación, con el que provocaba una mezcla de temor y respeto, como caminos para agilizar sus importantes e interesantes propuestas, y se manifestó siempre como enemigo acérrimo de la mediocridad. Prefirió pocos pero buenos amigos y no todo el mundo calificaba para incursionar en los laberintos complejos de su intimidad. Nunca pudo congeniar con la hipocresía, fue siempre más bien conciso y directo.

Con su temperamento me parece que buscaba consciente o inconscientemente dar cierta tensión a la relación y dejar muy claro que el mando estaba de su lado. Derrochaba mucha energía para lograr que las cosas salieran bien.

Por otro lado, su vehemencia servía para evidenciar de nuestro amigo una de sus más grandes virtudes, la capacidad para pedir perdón cuando percibía que se le había ido la mano en el gesto o en el comentario.

Tuvo maestros en el campo de la medicina con fuertes personalidades, tanto en nuestro país como en Inglaterra, de los que supo heredar esos rasgos de su carácter con los que logró ver cumplidos importantes deseos en su vida profesional.

No puedo omitir mencionar otra característica interesante, con la que le entregué mi admiración por los años que siguieron. Cuando tomaba la determinación de defender a un amigo o un ideal, no conocía barreras ni peligros. Se gestaba en los albores de los años 80 una huelga médica. En un Colegio de Médicos, repleto a reventar, con circuito cerrado de televisión en distintos aposentos y los ánimos caldeados hasta las entrañas, se presentó una moción para declarar "non grato" a la máxima autoridad de la Seguridad Social de aquel momento. El ambiente estaba dominado por la furia, la subjetividad, la intolerancia y la determinación y, en esas condiciones, frente a aquel escenario de rostros encendidos y amenazantes, Alfredo pidió la palabra, atravesó el salón con indiscutida determinación, tomó el micrófono y temerariamente habló con elocuencia para oponerse a aquella moción, que él sintió que innecesariamente ofendía a quien fue su amigo y mentor de muchos años. Este gesto le valió severas críticas y enemistades, pero otros supimos valorar su coraje para enfrentar un mar encrespado, asumiendo las consecuencias en todos sus extremos, sin remos y sin salvavidas.
Desde la perspectiva de sus logros e iniciando con su condición de estudiante universitario, mantuvo en forma permanente una actitud de crítica frente a las condiciones socioeconómicas y políticas prevalentes y participó en diversas luchas populares y estudiantiles reivindicativas desde una posición de liderazgo, llegando a ocupar el cargo de Vicepresidente de la Federación de Estudiantes de la UCR.

Se gradúa como especialista en Medicina Interna y en Gastroenterología en la Universidad de Costa Rica, entidad con la que desarrolla un vínculo amoroso y un noviazgo que no abandonó hasta el final de sus días. Alfredo se ancló en la Universidad con una pasión que pocos entenderían.

Se desplaza a Inglaterra donde estudia Hepatología en el Royal Free Hospital con su respetada Dame Sheila Sherlock, estableciendo con ese país y su gente relaciones de amistad, que lo trasladaban año tras año, con la excusa de cursos de refrescamiento, a llenarse de nuevo de la austeridad y cultura de su vetusto y oscuro Londres. Pero es que además cuando Alfredo no estaba en Inglaterra, Inglaterra estaba en Alfredo, en sus vivencias cotidianas y en sus añoranzas.

A su regreso de Inglaterra inicia labores como médico especialista en el Servicio de Gastroenterología del Hospital México. Pienso que el aporte a ese servicio y al hospital en general se relaciona con sus inquietudes en el campo de la investigación, llegando a tener más de 40 pu-blicaciones en revistas nacionales e internacionales, y a obtener muy joven el título de Catedrático de la Escuela de Medicina.

Funda a principios de los años ochenta la Unidad de Hígado, con la que logra desarrollar el conocimiento en este campo, y aglutina a un grupo de estudiantes y profesionales jóvenes de diversas disciplinas, con quienes se aboca al estudio persistente de pacientes y temas conexos, durante no menos de 10 años. De ese grupo nacieron amistades que Alfredo supo cosechar y mantener unidos hasta la fecha. Pero es que además generó vínculos para el diagnóstico y la investigación con el CBMC de la UCR y con el ICMRT de la Universidad de Louisiana, de donde se generaron resultados y publicaciones de gran utilidad para los pacientes y la Institución.

De esa pasión por la Universidad y por lo universitario llega a ocupar cargos como miembro de la asamblea representativa de la Escuela de Medicina en varios períodos, director de la Unidad de Postgrado en Gastroenterología, coordinador de la Sección de Fisiopatología del Departamento de Área Clínica en el Hospital México, director del Postgrado de Área Médica del SEP-Cendeisss, director General de Postgrado, director Ejecutivo del Cendeisss, miembro de la asamblea colegiada representativa de la UCR.

En el Hospital México fue primero Jefe de Clínica y luego Jefe del Servicio de Gastroenterología. 
Fue además miembro de múltiples asociaciones y sociedades médicas, nacionales e internacionales.

Pienso que sus familiares y amigos podemos estar satisfechos por la labor cumplida por Alfredo y tengo la sensación de que en alguna medida él también lo estaba. Entre sus aspiraciones para los próximos años nunca mencionó su interés por ningún otro cargo administrativo, docente ni político, aunque capacidad le sobrara para ello. Parece que sus intenciones a corto plazo estaban más orientadas a la vida sosegada de una merecida pensión, viajando, conociendo, escuchando un concierto en el Royal Albert Hall, o degustando una ginebra con agua quinada en una interesante conversación con sus amigos, ya fuera de éste o de aquel lado del charco.

No puedo dejar de mencionar, aunque ya lo hizo de una manera extraordinaria su hijo Ricardo, otras facetas de la vida de Alfredo: recuerdo por ejemplo su risa, con pretensiones de carcajada, fuerte y breve y generalmente iba acompañada de algún comentario; su conversación, fue amena, ya que era una persona que escuchaba y tenía argumentos y contrargumentos inteligentes con los que por supuesto teníamos resueltos los problemas del país, de la caja y de la universidad; su amor por el arte pero principalmente por la música clásica, de la cual era un experto y con la que incursionaba en su paz interior, perdiéndose en ese éxtasis maravilloso que existe entre notas y silencios; su sensibilidad y su preocupación por los pobres y por la naturaleza que quedaron plasmadas en su testamento; su absoluto rechazo por el lujo y las vanidades y su preclara capacidad intelectual que le deparó singulares amistades del mundo de la ciencia, el arte y la política, así como su amor y admiración por sus hijos, quienes cada vez más acaparaban la atención de nuestras tertulias. Se cuenta eso sí, que fue uno de los peores bailarines que la historia conoció.

Para algunos de nosotros la ausencia de Alfredo es realmente dolorosa por la cantidad de inquietudes y quijotadas que compartimos, pero servirán de recuerdo para que su llama se mantenga viva alimentando en nuestro interior el temple, el amor, la entrega, la humildad y el gozo. 